FACILITATING THE EXPRESSION OF EMOTIONS

Facilitating the Expression of Emotions by Alleged Victims of Child Abuse During Investigative Interviews Using the Revised NICHD Protocol

Authors:

Yael Karni-Visel' $\varangle$, Irit Hershkowitz², Michael E. Lamb', Uri Blasbalg'

1 University of Cambridge, UK.

2 University of Haifa, Israel

$\varangle$ Corresponding author:

Yael Karni-Visel, PhD

University of Cambridge, UK.

E-Mail: yaelvisel@gmail.com 


\title{
FACILITATING THE EXPRESSION OF EMOTIONS
}

\begin{abstract}
Children's testimony is often critical to the initiation of legal proceedings in abuse cases. In forensic interviews, the expression of emotions can powerfully enhance both the quality of children's statements and perceptions that their statements are coherent and credible. However, children rarely express their emotions when reporting abusive events. The Revised NICHD Protocol (RP) was designed to emphasize socioemotional communication during forensic interviews and thus should be associated with more extensive and diverse expressions of emotions by alleged victims of abuse. The present study focused on forensic interviews (178 using the Revised and 100 using the Standard NICHD Protocol) with victims of physical child abuse whose allegations were corroborated using independent evidence. Detailed content coding showed that the RP was associated with the expression of more different emotions, more expression of abuse-related emotions, and more expression of emotions related to the interview context. Emotional expressiveness was associated with increased informativeness, and the association between the type of protocol and informativeness was fully mediated by emotional expressiveness. These results suggest that the Revised Protocol facilitates the expression of emotions by alleged victims of abuse in a way that enhances the value of children's testimony in multiple ways.
\end{abstract}




\section{FACILITATING THE EXPRESSION OF EMOTIONS}

Child physical abuse may have serious long-term consequences for children's emotional and physical well-being (for review, see Teicher \& Samson, 2016). Unfortunately, abuse often remains unrecognized and victims may need to provide rich and detailed information about their experiences in order to inform legal procedures and treatment providers (e.g., Paine \& Hansen, 2002; Pelton, 2015). Although the factual content of children's accounts has been the main focus of memory researchers, the expression of emotions related to either the event or the forensic interview context have received much less attention (Fivush \& Baker-Ward, 2005) even though emotional expression is an important component of testimonial coherence (Snow, Powell, \& Murfett, 2009; Westcott \& Kynan, 2004). The aim of the current study was to determine whether sensitive interviewing affected the verbal expression of emotions by alleged abuse victims during forensic interviews.

\section{Benefits of Emotional Expressions}

Many theorists (e.g., Perls, 1969; Rogers, 1951) and researchers (e.g., Lane, Ryan, Nadel, \& Greenberg, 2015; Rohde, Stein, Pascual-Leone, \& Caspar, 2015) have proposed that "emotional work" can be beneficial in clinical settings and thus that accessing and exploring painful emotions and negative feelings can be therapeutic (Lane et al., 2006). Emotional work, including the recognition of varied and deep feelings and emotions, can also be beneficial when the listener is a significant other (Rimé, 2009) or simply an attentive listener (Pennebaker, 2012). Empirical research has also identified several benefits associated with the expression of positive and negative emotions by children. In the process of adaptive coping, emotional expression helps children understand (Bird \& Reese, 2006; Marin, Bohanek, \& Fivush, 2008) and evaluate or regulate their feelings and thoughts (Laible, 2004) about past events. Consistently, the suppression of negative as well as positive emotions is associated with psychopathological 


\section{FACILITATING THE EXPRESSION OF EMOTIONS}

symptoms and maladjustment (e.g., Gross \& Levenson, 1997). However, life story researchers have highlighted individual differences and have shown that some ways of creating personal narratives are less adaptive and growth-promoting than others (Greenhoot \& McLean, 2013). For example, adaptive coping is correlated with increased negative affect in preadolescents but not in adolescents (Styers \& Baker-Ward, 2013).

Engaging emotions enhances children's cognitive abilities such as better narration (Laible, 2004) and better assimilation of information (Pennebaker, 2012). Liwag and Stein (1995) showed that emotional cueing helped preschool children retrieve memories and that the reinstatement of emotions helped children provide high quality narratives. In addition to their mnemonic efficacy, accounts that make references to subjective reactions are perceived as more coherent (Snow et al., 2009; Westcott \& Kynan, 2004), making the reporters seem more credible (Cooper, Quas, \& Cleveland, 2014) and better (Castelli \& Goodman, 2014) witnesses. Thus, expressing emotions while disclosing abuse increases the effectiveness of child witnesses.

The expression of emotions also facilitates the coordination of interpersonal relationships by children (e.g., Dunn, Brown, \& Beardsall, 1991). Through mutually understood emotional signals, partners can assess each other's feelings and thus regulate each other's behavior more insightfully (for a review, see Gross, 2002). Moreover, negative emotional expressions may signal vulnerability and thus tend to disarm (Greenberg \& Johnson, 1990) and elicit sensitive and appropriate support from professionals (Kennedy-Moore \& Watson, 2001; Vatne, Ruland, Ørnes, \& Finset, 2011).

\section{Children's Emotional Expressiveness in Forensic Contexts}

Although emotional expression can be extremely beneficial, children, especially preschoolers and young children, rarely express their emotions spontaneously when describing 


\section{FACILITATING THE EXPRESSION OF EMOTIONS}

past events including incidents of abuse in forensic investigations, and their expressions tend to be brief and sporadic (Katz, Paddon, \& Barnetz, 2016; Westcott \& Kynan, 2004). The common lack of emotional expressiveness in legal contexts is often viewed negatively (Castelli \& Goodman, 2014; Lyon, Scuich, Choi, Handmaker, \& Blank, 2012; Wessel, Eilertsen, Langnes, Magnussen, \& Melinder, 2016; Wessel, Magnussen, \& Melinder, 2013). However, in some contexts such as familial and therapeutic settings, alleged victims $d o$ report a range of emotions, including sadness, fear, anger, shock, and ambivalence towards the investigation itself as well as to the abusive events (Goodman-Brown, Edelstein, Goodman, Jones \& Gordon, 2003).

\section{Facilitating Emotional Expression}

Children are capable of expressing a variety of emotions yet rarely reveal them in forensic contexts, especially without sensitive support from skilled interviewers (Ahern \& Lyon, 2013). Participating in a dialogue that encourages emotional expression may increase children's awareness of the interviewers' expectations (Ahern \& Lyon, 2013). Klemfuss, Milojevich, Yim, Rush, and Quas (2013) found that children who experienced high stress during an event benefited more from interviewer support and provided richer emotional information than either children who experienced low stress during the event or children who experienced high stress but were interviewed under neutral conditions. Similarly, Lyon et al. (2012) found that supportive 'how did you feel?' questions elicited reports about internal processes. Ahern and Lyon (2013) later showed that cued retrieval questions ('You said you felt [emotion], tell me more about it')

yielded many references to emotional expressions as well as richer narratives.

\section{Support and the Quality of Children's Testimony}

Several studies have demonstrated the beneficial effects of support on the quality of children's testimony. However, although laboratory analog studies have established that 


\section{FACILITATING THE EXPRESSION OF EMOTIONS}

supportive interviews elicit more accurate information than do neutral or non-supportive interviews (see Saywitz, Wells, Larson, \& Hobbs, 2016, for a review), there was until recently no clear evidence of an association between support and informativeness in field studies (Hershkowitz, 2009; Lewy, Cyr \& Dion, 2015). One possibility is that the effect of support on memory retrieval is not direct but is rather mediated by other emotional processes (Saywitz et al., 2016) such as decreased anxiety (Quas, Bauer, \& Boyce, 2004) or perceived self-efficacy

(Bottoms et al., 2007; Bottoms et al., 2002). Indeed, a recent field study showed that the effect of support on informativeness was partially mediated by children's decreased reluctance (Blasbalg et al., 2018).

\section{The Revised NICHD Protocol (RP)}

A recent revision of the NICHD Investigative Interview Protocol was designed to help interviewers conduct more emotionally supportive forensic interviews (Lamb, Brown, Hershkowitz, Orbach, \& Esplin, 2018; Hershkowitz, Lamb, Katz, \& Malloy, 2013; Hershkowitz et al., 2017). The RP includes adjustments that emphasize rapport building and the provision of support during forensic interviews. Initial evaluations have revealed increases in the amount of support offered to reluctant children in the rapport-building phases of forensic interviews (Ahern, Hershkowitz, Lamb, Blasbalg, \& Winstanley, 2014; Hershkowitz et al., 2013), and higher rate of disclosure (Hershkowitz, Lamb, \& Katz, 2014) when the RP rather than the SP was used. Based on these encouraging results, the Israeli Child Investigation Service decided to mandate use of an updated version of the RP throughout the country and an extensive training program was held for all forensic interviewers in the Service (Hershkowitz et al., 2017).

Comparing SP and RP interviews, Ahern, Hershkowitz, Lamb, Blasbalg, and Karni-Visel (2017) found that, in the RP condition, children disclosed more readily, requiring fewer prompts. 


\section{FACILITATING THE EXPRESSION OF EMOTIONS}

In study of interviews conducted using RP, interviewer supportive comments facilitated children's expressions of emotion, which in turn led to increased informativeness (Karni-Visel, Hershkowitz, Lamb, \& Blasbalg, 2018b).

The goal of the present study was to determine whether use of the RP led to increases in children's emotional expressiveness during forensic interviews. We specifically focused on both emotional expressions related to the abusive events and emotional expressions related to the interview in both SP and RP interviews. It was hypothesized that children interviewed using the RP would express more emotions about the interview and about the abusive events and would be more forensically informative. It was also hypothesized that children interviewed using the RP would report a more diverse array of emotions than would children interviewed using the SP.

\section{Participants}

\section{Method}

A total of 278 interviews (168 with boys; 110 with girls), were conducted with 4.06- to 13.98-year-old children $(M=9.28, S D=2.42)$ who disclosed physical abuse by family members. 100 children ( 68 boys) averaging 8.88 years $(S D=2.74)$ of age were interviewed using the $S P$, whereas 178 (100 boys) whose average age was 9.43 years $(S D=2.32)$ were interviewed using the RP. The SP interviews were conducted in all regions of Israel during an 18-month-long period (between January 2013 and June 2014) and the RP interviews during a subsequent 19month-long period (between August 2014 and February 2016) by 61 child investigators from the Israeli Child Investigation Service in the Ministry of Welfare and Social Services. The SP interviews were conducted by 48 interviewers who had been extensively trained to use the Standard NICHD Protocol and were experienced forensic interviewers, regularly conducting hundreds of them every year. The RP interviews were conducted by 40 investigators ( 27 of them conducted also the SP interviews) who were intensively trained to use the RP, whereas the SP 


\section{FACILITATING THE EXPRESSION OF EMOTIONS}

interviews were conducted when its use was mandatory prior to the implementation of the RP. Interviews selected for this study were the first during the specified periods that met the inclusion criteria: They were conducted in the children's educational settings (to avoid possible intervention of the alleged perpetrator), and the allegations were deemed valid or substantiated based on independent evidence (63\% eyewitness reports, $14 \%$ evidence of wounds and bruises, $17 \%$ suspect admissions), or based on prior disclosures to professionals (6\%). The current study was approved by the Ministry of Welfare and Social Services as well as by the authors' University ethics committees.

\section{The NICHD Investigative Interview Protocol}

The NICHD Protocol is fully structured, covering all phases of investigative interviews. The guide encourages interviewers to exhaustively probe children's memory using free-recall prompts before asking directive questions, with few option-posing questions asked only when necessary to elicit critical information. In the introductory phase, interviewers introduce themselves, clarify the children's task (i.e., the need to describe experienced events truthfully and in detail), and explain the ground rules and expectations (i.e., that children can and should say, 'I don't know', 'I don't understand', or correct the interviewers when appropriate). The rapport-building phase comprises two sections. The first is a structured open-ended section in which children are encouraged to provide personally meaningful information (e.g., what they like to do). In the second section, children are prompted to describe in detail at least one recently experienced event in order to further develop rapport between children and interviewers and to familiarize children with the level of detail expected of them. In addition to its rapport building function, this phase of the interview is designed to simulate both the open-ended investigative strategies and the retrieval of episodic memories that will take place in the substantive phase. 
FACILITATING THE EXPRESSION OF EMOTIONS

\section{The Revised NICHD Protocol (RP)}

The Revised Protocol (RP) represents a revision of the Standard NICHD Investigative Protocol (SP) and is characterized by enhanced emphasis on supportive interviewing (for a detailed description, see Lamb et al., 2018). First, in order to promote children's emotional comfort, trust, and cooperation, the RP recommends rapport building before (rather than after) explanation of the ground rules. Second, the guide explains how interviewers might use several types of non-suggestive but supportive comments during the interviews (see Table 1) by, for example, showing appreciation, encouraging children to share their emotions and experiences, mentioning the availability of the interviewer as a supportive figure, providing direct encouragement, and offering help or making small gestures of good will. Third, the RP also provides specific instructions for using both contingent support in response to the children's expressions of emotions and to prompt for emotions when children do not mention them spontaneously. Interviewers are guided to acknowledge, contain, echo and explore emotions expressed in the pre-substantive part of the interview and to prompt for emotions if children do not mention them spontaneously. Interviewers are guided to use the same techniques to address expressions of emotion during the substantive phases of the interviews.

\section{Data coding}

Recordings of the interviews were transcribed and checked to ensure their completeness and accuracy. All transcripts were coded by native speakers of Hebrew. For some analyses, the length of each of the interview phases was introduced as a control variable and was quantified by counting the total number of interviewer-child conversational turns. The interviewer interventions and child responses described below were coded as present or absent in each conversational turn as in Hershkowitz et al.'s (2017) study. 


\section{FACILITATING THE EXPRESSION OF EMOTIONS}

Indices of support were categorized as: (a) expressions of emotional support, (b) expressions designed to establish rapport, (c) references to the interviewer's trustworthiness, (d) positive reinforcements of the child's efforts, and (e) expressions of encouragement (see Table 1).

Emotional expressions were coded whenever the children used words describing emotions (e.g., 'afraid', 'happy') or emotional metaphors (e.g., 'I felt like I wanted to bang my head against the wall') that appear on common emotion rating scales such as the PANAS (Watson, Clark, \& Tellegen, 1988) or in either Roget's Thesaurus or standard Hebrew dictionaries in nominal, verbal, or adjectival forms. Emotional expressions included all morphological variants of the word (e.g., 'scared' included 'scary' and 'scare'). Coders distinguished between two types of emotions on the basis of their context: (a) emotions related to the event under investigation - whenever there were explicit verbal references to emotional states related to the event (e.g., 'I panicked when I saw him coming', 'I cried in my bed') or (b) emotions related to the interview context whenever there were explicit verbal references to emotional states related to the interview (e.g., 'I am afraid to tell you', 'now I feel relieved'). In order to assess the variety of emotions expressed, every emotional expression was coded and counted once whenever children used words describing their emotions (e.g., 'scared' was counted as a one word, 'shocked' was counted as an additional word etc.). Thus, the number of different emotions referenced throughout the interview was counted.

In addition, each of the children's utterances was coded for the presence or absence of specific forensic details, following a technique first developed by Yuille and Cutshall (1986). Details involved the identification of individuals, objects, or events, and descriptions of their features (e.g., appearance, actions, locations). Details were only counted when they added to understanding of the target incidents, so restatements of facts were not counted. 


\section{FACILITATING THE EXPRESSION OF EMOTIONS}

Four raters first established inter-rater reliability on a separate set of transcripts. To ensure that high levels of reliability were maintained throughout the course of coding, $20 \%$ of the transcripts were independently recoded. Coders were blind to the research hypotheses. $K$ alpha inter-rater index coefficients (Hayes \& Krippendorff, 2007) for support, emotions, and informativeness were $0.88,0.89$, and 0.83 , respectively.

\section{Analytic approach}

To assess the associations among the type of interview protocol, children's emotional expressions, and children's informativeness, we compared interviews in the RP and SP conditions. Preliminary Generalized Linear Model (GLMM) tests were conducted to determine whether the RP and SP groups differed with respect to the child's age, gender, relationship to the suspect, or the severity of abuse (cases involving injury, hitting with an object, or hitting without an object were classified as severe, moderate, and mild, respectively). When analyzing emotions related to the interview context, the total number of turns in the interview was calculated, whereas when analyzing emotions related to abusive events, we only counted the total number of turns in the substantive phase of the interview. A univariate analysis of variance was then used to compare the variety of different emotions expressed in interviews conducted using either the RP or the SP while GLMM analyses tested our hypotheses about Protocol type using dichotomous outcome variables (the presence or absence of emotions or details in each utterance). The mixed-effects approach was selected because it accommodates nested (Hayes, 2006), and unbalanced (varying numbers of turns per interview) data (Heck, Thomas, \& Tabata, 2013). The Monte Carlo method was then used to determine whether the effects of Protocol were mediated by the children's emotional expressiveness. This involved constructing a sampling distribution of the indirect (i.e., mediated) effect using point estimates of mediation paths and the 


\section{FACILITATING THE EXPRESSION OF EMOTIONS}

asymptotic covariance matrix of those estimates with 20,000 resamples. The indirect effect was deemed significant if the confidence interval did not include zero (Preacher \& Selig, 2012).

\section{Results}

\section{Preliminary Analyses}

Preliminary GLMM analyses revealed that the groups did not differ significantly with respect to their key characteristics (the child's age, gender, relationship to the suspect, or the severity of abuse), but there were non-significant trends with respect to age $(F(1,276)=3.243$, $p$ $=.073)$ and gender $(\mathrm{F}(1,276)=3.765, \mathrm{p}=.053)$, so the effects of these two independent variables were controlled for statistically in all the analyses reported below.

\section{Variety of Emotions Expressed}

Overall, children made reference to 143 different emotions; 115 different emotions were referenced during RP interviews and 80 different emotions were referenced in SP interviews (52 specific emotions were referenced in both SP and RP interviews). On average, children expressed $7.29(S D=4.33)$ different emotions in RP interviews but only $4.85(S D=3.71)$ in SP interviews $(\mathrm{F}(1,273)=21.33, \mathrm{p}<0.001)$. Child age and gender significantly predicted variety of expression: older children $(\mathrm{F}(1,273)=27.05, \mathrm{p}<0.001)$ and girls $(\mathrm{F}(1,273)=15.93, \mathrm{p}<0.001)$ expressed more varied emotions than younger children and boys, respectively. The control variable - length of the relevant interview phase - was positively correlated with the variety of emotions expressed $(F(1,273)=18.82, \mathrm{p}<0.001)$, but the effects of Protocol type remained significant after controlling for the effects of phase length, gender, and age, and the cited statistics reflect these adjustments.

Emotional Expressions Related to the Interview Context 


\section{FACILITATING THE EXPRESSION OF EMOTIONS}

Similarly, GLMM analyses revealed that emotional expressions related to the interview/interviewer were more likely to be elicited in $\mathrm{RP}(\mathrm{M}=0.03, S D=0.16)$ than in $\mathrm{SP}(\mathrm{M}$ $=0.01, S D=0.08)$ interviews, $(\beta=0.31, S E=0.06, p<.001,95 \% C I[1.22,1.52])$. Child age and gender did not have significant effects (see Table $2 \mathrm{~A}$ ).

\section{Emotional Expressions About Events}

GLMM analyses focused on emotional expressions related to the abusive events showed that emotional expressions related to the alleged abuse were more likely to be elicited in the substantive phases of $\mathrm{RP}(\mathrm{M}=0.06, S D=0.24)$ rather than $\mathrm{SP}(\mathrm{M}=0.04, S D=0.21)$ interviews, $(\beta=0.30, S E=0.13, p=0.019,95 \% C I[1.05,1.73]$. Child age and gender significantly predicted emotional expression; older children $(\beta=0.09, S E=0.03, p<0.001,95 \% C I[1.07,1.18]$, and girls $(\beta=0.67, S E=0.12, p<.001,95 \% C I[1.54,2.46]$ expressed more emotions than did younger children and boys, respectively (see Table 2 B).

\section{Substantive details}

The association between the type of protocol used and the number of substantive details reported was then tested (see Table 3). Use of the RP was not associated with the production of more details than use of the SP but the number of emotional expressions related to the abuse was positively correlated with the number of details reported $(\beta=0.46, S E=0.06, p<0.001,95 \% C I$ $[1.40,1.78])$. Gender also had a significant effect $(\beta=-0.14, S E=0.07, p=0.048,95 \% C I$ $[0.76,1.00])$ : boys provided more details than girls did. Child age did not have significant effects. Although there was no direct association between the protocol and informativeness, children's emotional expressions mediated the association between support and informativeness. A Monte Carlo model showed that the indirect effect of support on informativeness was significant [95\% confidence interval (Lower Level $(\mathrm{LL})=0.0207$, Upper Level $(\mathrm{UP})=0.2608 \mathrm{p}<0.05)]$. 


\section{FACILITATING THE EXPRESSION OF EMOTIONS}

\section{Discussion}

Accessing and exploring emotional expressions can have important implications for children's cognitive, psychological, and health outcomes (e.g., Bird \& Reese, 2006; Marin et al., 2008). In legal contexts, children are often expected to provide rich accounts about the events they have experienced in order to trigger interventions (e.g., Cross \& Hershkowitz, 2017; Paine \& Hansen, 2002). While most previous research on forensic interviews has focused on the richness and accuracy of children's testimony (Ahern et al., 2014; Hershkowitz et al., 2013; Saywitz et al., 2016), the current study also examined the emotions expressed by children who were alleged victims of physical abuse by family members, showing that interviewers facilitated more frequent and more varied emotional expressions by children when they used the RP rather than the SP, and, importantly, that references to emotions was associated with increased informativeness about the alleged abuse.

The use of the RP was thus associated with a more diverse array of expressed emotions than was use of the SP. Expressing a wide range of emotions is associated with psychological and social benefits that include enhanced emotional regulation (e.g., Lunkenheimer, Hollenstein, Wang, \& Shields, 2012), better psychological flexibility (Lubart \& Getz, 1997), and improved communication (Gordon, 1961) whereas repetitively expressing the same emotions might interfere with adaptive coping (see Kennedy-Moore \& Watson, 2001, for a review). Previous research has measured the diversity of emotional expression in conversations between children and parents (e.g., Bauer et al., 2005; Cervantes \& Callanan, 1998), especially about traumatic events (Fivush \& Wang, 2005), but this was the first study focused on forensic interviews.

The current study also showed that use of the RP was associated with increases in the number of times children referred to emotions related to the interview context. This topic has not 


\section{FACILITATING THE EXPRESSION OF EMOTIONS}

been the focus of much research previously, with some studies examining children's retrospective evaluations of their emotional reactions to the interview (Katz et al., 2014) or the investigative process (Westcott \& Davies, 1996). In retrospect, children often describe disclosure as an ambivalent process marked by negative emotional states such as fear, shame, and guilt (Goodman-Brown et al., 2003; Hershkowitz, Lanes, \& Lamb, 2007; Kuehnle \& Connell, 2011) which often cause reluctance to disclose abuse, particularly when the offender is a family member (Hershkowitz et al., 2005). Promoting the interviewers' attunement to the children's emotional needs may have helped relieve some of the children's emotional distress (Pennebaker, 2012; Rimé, 2009).

Importantly, the current study showed that interviewers using the RP also elicited more frequent references to emotions associated with the abusive events under investigation. Rich verbal descriptions of emotions elucidate the impact of reported events on the individuals concerned (Bauer et al., 2005) and make the children seem coherent (Snow et al., 2009; Westcott \& Kynan, 2004), credible (Cooper et al., 2014), and effective as witnesses (Castelli \& Goodman, 2014). Previous analog studies have shown that children who experienced a more stressful event and were questioned in a supportive manner (with mostly nonverbal demonstrations of support) provided proportionally more information about internal states, including cognitions and emotions (Ahern \& Lyon, 2013; Klemfuss et al., 2013; Lyon et al., 2012).

In addition to their utility in fostering the credibility of children's testimony, we found that emotions fostered the retrieval of forensically valuable information. Previous analog studies have shown that informativeness (e.g., Davis \& Bottoms, 2002; Quas, Bauer, \& Boyce, 2004) and accuracy (for meta-analysis, see Saywitz et al., 2016) increase when interviewers adopt a supportive demeanor. There is also substantial evidence that emotions can enhance children's 


\section{FACILITATING THE EXPRESSION OF EMOTIONS}

memory retrieval (see Hamann \& Stevens, 2014 for review) but this was the first study to examine displays of emotion in forensic contexts and to show that the expression of emotions accounts for the association between supportive interviewing and informativeness, suggesting an indirect pathway between support, emotion reinstatement, and retrieval.

The present study was conducted after a nationwide program in which interviewers were trained to use the RP and thus employ supportive but non-suggestive strategies throughout forensic interviews, especially when children expressed emotions (Ahern et al., 2017; Hershkowitz et al., 2017). The effects reported here are likely attributable to two processes. First, interviewers were trained to provide contingent support in response to the children's expressions of emotions and to prompt for emotions if children did not mention them spontaneously (Hershkowitz et al., 2017). Children often need to be specifically directed to describe emotions (e.g., Griffin, 1995), because their spontaneous reports tend to focus on actions and outcomes. Participating in a dialogue that encourages emotional expression may increase children's awareness of the interviewers' expectations (Ahern \& Lyon, 2013), with supportive comments following the expression of emotions encouraging children to express further emotions (Karni-Visel et al., 2018b).

Second, and more broadly, the RP emphasizes the expression of support and encouragement by interviewers throughout the interview. A supportive demeanor is known to empower children (Davis \& Bottoms, 2002), promote child-interviewer engagement (Cohen, Mannarino, \& Deblinger, 2006), and reduce feelings of intimidation (Greenstock \& Pipe, 1996, 1997). Interviewers who express interest and foster openness and acceptance may increase the children's willingness to report emotional information (Cohen et al., 2006) and to describe meaningful experiences (Salmon \& Reese, 2015). 


\section{FACILITATING THE EXPRESSION OF EMOTIONS}

\section{Limitations and Suggestions for Future Research}

The insights gained in the current study are constrained by its limitations. This study examined only children's emotional language, thereby excluding nonverbal information conveyed by facial expressions, voice pitch, and body language. Future research should examine the complementary effects of the RP on nonverbal expressions of emotion. In addition, the study only included children who reported physical abuse. Different effects might have been apparent if other forms of maltreatment had been examined (Hershkowitz et al., 2005). Another major limitation stems from the nonexperimental design of the current study, which precludes causal inferences. Although there is good evidence that supportive interviewing is desirable (Saywitz et al., 2015), experimental research remains necessary. In addition to the child and case characteristics already controlled for in this study, other factors, such as socioeconomic status (SES), might also have affected the children's socio-emotional skills (Cutting \& Dunn, 1999). Finally, cultural and subcultural factors may have affected the findings because the study was conducted in Israel using a sample comprising native speakers of Hebrew. In this study, the number of forensically relevant details elicited from the children using each of the Protocols did not differ. This is likely because use of the RP is associated with a higher disclosure rate, with some reluctant disclosers offering very few details about their alleged experiences. Many of these children might not have made allegations in SP interviews and would thus have been excluded from the study, which focused only on interviews in which children made allegations.

\section{Implications for Practice and Policy}

The study demonstrated that the RP helps children to overcome emotional barriers and to express their emotions in a way that increases the informativeness and credibility of child witnesses. Further efforts should be dedicated to developing and evaluating non-suggestive yet 


\section{FACILITATING THE EXPRESSION OF EMOTIONS}

supportive interviewing techniques to facilitate emotional expression by those who have more difficulty expressing emotions, such as young children and boys. Practitioners should also acknowledge that children who disclose abuse may still find it difficult to express their emotions in forensic settings and avoid letting this bias their judgments about the children's credibility (Wessel et al., 2016; Wessel et al., 2013). Exploring and facilitating constructive expressions of emotions is a complex interviewing skill that is acquired only after extensive training (Hershkowitz et al., 2017) and may be emotionally taxing for professionals. It may thus be important to provide opportunities for supervision (Gibbs, 2001) that promotes self-awareness and encourage reflective processing of the professionals' own negative emotions so that they are better attuned to children's emotional needs. 
FACILITATING THE EXPRESSION OF EMOTIONS

\section{References}

Ahern, E. C., Hershkowitz, I., Lamb, M. E., Blasbalg, U., \& Karni-Visel, Y. (2018). Examining reluctance and emotional support in forensic interviews with child victims of substantiated physical abuse. Applied Developmental Science. Advance online publication. Doi:10.1080/10888691.2017.1387057

Ahern, E. C., Hershkowitz, I., Lamb, M. E., Blasbalg, U., \& Winstanley, A. (2014). Support and reluctance in the pre-substantive phase of alleged child Abuse victim investigative interviews: Revised versus Standard NICHD Protocols. Behavioral Sciences \& the Law, 32(6), 762-774. Doi:10.1002/bsl.2149

Ahern, E.C, \& Lyon, T.D. (2013). Facilitating maltreatment children's use of emotional language. Journal of Forensic Social Work, 3, 176-203.

Doi:10.1080/1936928X.2013.854124

Aldridge, M., \& Wood, J. (1997). Talking about feelings: Young children's ability to express emotions. Child Abuse \& Neglect, 21(12), 1221-1233.

Bauer, P. J., Stark, E. N., Lukowski, A. F., Rademacher, J., Van Abbema, D. L., \& Ackil, J. K. (2005). Working together to make sense of the past: Mothers' and children's use of internal states language in conversations about traumatic and nontraumatic events. Journal of Cognition and Development, 6(4), 463-488.

Doi:10.1207/s15327647jcd0604_2

Bird, A., \& Reese, E. (2006). Emotional reminiscing and the development of an autobiographical self. Developmental Psychology, 42(4), 613. Doi:10.1037/0012-1649.42.4.613

Blasbalg, U., Hershkowitz, I., \& Karni-Visel, Y. (2018). Support, reluctance, and production in child abuse investigative interviews. Psychology, Public Policy, and Law, 24(4), 518. Doi:10.1037/law0000183 


\section{FACILITATING THE EXPRESSION OF EMOTIONS}

Castelli, P., \& Goodman, G. S. (2014). Children's perceived emotional behavior at disclosure and prosecutors' evaluations. Child Abuse \& Neglect, 38(9), 1521-1532.

Doi: 10.1016/j.chiabu.2014.02.010

Cervantes, C. A., \& Callanan, M. A. (1998). Labels and explanations in mother-child emotion talk: Age and gender differentiation. Developmental Psychology, 34(1), 88-98.

Cohen, J. A., Mannarino, A. P., \& Deblinger, E. (2006). Treating Trauma and Traumatic Grief in Children and Adolescents. Guilford Press.

Cooper, A., Quas, J. A., \& Cleveland, K. C. (2014). The emotional child witness: Effects on juror decision-making. Behavioral Sciences \& the Law, 32, 813-828.

Doi: $10.1002 / \mathrm{bs} 1.2153$

Cutting, A. L., \& Dunn, J. (1999). Theory of mind, emotion understanding, language, and family background: Individual differences and interrelations. Child Development, 70, 853-865.

Davis, S. L., \& Bottoms, B. L. (2002). Effects of social support on children's eyewitness reports: A test of the underlying mechanism. Law and Human Behavior, 26(2), 185.

Doi: 10.1023/A:1014692009941

Dunn, J., Brown, J., \& Beardsall, L. (1991). Family talk about feeling states and children's later understanding of others' emotions. Developmental Psychology, 27(3), 448.

Edwards, D. (1999). Emotion discourse. Culture \& Psychology, 5(3), 271-291.

Fivush, R. (1991). Gender and emotion in mother-child conversations about the past. Journal of Narrative and Life History, 1(4), 325-341. Doi: 10.1075/jnlh.1.4.04gen

Fivush, R., \& Baker-Ward, L. (2005). The search for meaning: Developmental perspectives on internal state language in autobiographical memory. Journal of Cognition and Development, 6(4), 455-462. Doi:0.1207/s15327647jcd0604_1 


\section{FACILITATING THE EXPRESSION OF EMOTIONS}

Fivush, R., McDermott-Sales, J., \& Bohanek, J.G. (2008). Meaning making in mothers' and children's narratives of emotional events. Memory, 16(6), 579-594.

Doi: 10.1080/09658210802150681

Fivush, R., \& Wang, Q. (2005). Emotion talk in mother-child conversations of the shared past: The effects of culture, gender, and event valence. Journal of Cognition and Development, 6(4), 489-506. Doi:10.1207/s15327647jcd0604_3

Gibbs, J. A. (2001). Maintaining front-line workers in child protection: A case for refocusing supervision. Child Abuse Review, 10(5), 323-335. Doi:10.1002/car.707

Goodman-Brown, T. B., Edelstein, R. S., Goodman, G. S., Jones, D. P., \& Gordon, D. S. (2003). Why children tell: A model of children's disclosure of sexual abuse. Child Abuse \& Neglect, 27(5), 525-540. Doi:10.1016/S0145-2134(03)00037-1

Gordon, W. 1. J. (1961). Synectic: The Development of Creative Capacity. NY: Harper \& Row.

Greenberg, L. S. (2004). Emotion-focused therapy. Clinical Psychology \& Psychotherapy, 11, 3. Doi: $10.1002 /$ cpp.388

Greenberg, L. S., \& Johnson, S. M. (1990). Emotional change processes in couples therapy. Emotions and the Family: For Better or for Worse, 137-153.

Greenhoot, A. F., \& McLean, K. C. (2013). Introduction to this special issue meaning in personal memories: Is more always better?. Memory, 21, 2. Doi: 10.1080/09658211.2013.756611

Greenstock, J., \& Pipe, M. E. (1996). Interviewing children about past events: The influence of peer support and misleading questions. Child Abuse \& Neglect, 20, 69-80.

Greenstock, J., \& Pipe, M. E. (1997). Are two heads better than one? Peer support and children's eyewitness reports. Applied Cognitive Psychology, 11, 461-483.

Griffin, S. (1995). A cognitive-developmental analysis of pride, shame, and embarrassment in 


\section{FACILITATING THE EXPRESSION OF EMOTIONS}

middle childhood. Self-Conscious Emotions: The Psychology of Shame, Guilt, Embarrassment, and Pride, 219-236.

Gross, J. J. (2002). Emotion regulation: Affective, cognitive, and social consequences. Psychophysiology, 39(3), 281-291. Doi:10.1017/S0048577201393198

Gross, J. J., \& Levenson, R. W. (1997). Hiding feelings: The acute effects of inhibiting negative and positive emotion. Journal of Abnormal Psychology, 106(1), 95-103.

Hayes, A. F. (2006). A primer on multilevel modeling. Human Communication Research, 32, 385-410. Doi:10.1111/j.1468-2958.2006.00281.x

Hayes, A. F., \& Krippendorff, K. (2007). Answering the call for a standard reliability measure for coding data._Communication Methods and Measures,_1(1), 77-89. Doi: 10.1080/19312450709336664

Heck, R. H., Thomas, S., \& Tabata, L. (2013). Multilevel Modeling of Categorical Outcomes Using IBM SPSS. Routledge Academic.

Hershkowitz, I. (2006). Delayed disclosure of alleged child abuse victims in Israel. American Journal of Orthopsychiatry, 76, 444-450. Doi:10.1037/0002-9432.76.4.444

Hershkowitz, I., Ahern, E. C., Lamb, M. E., Blasbalg, U., Karni-Visel, Y., \& Breitman, M. (2017). Changes in interviewers' use of supportive techniques during the Revised Protocol training. Applied Cognitive Psychology, 31(3), 340-350. Doi: 10.1002/acp.3333

Hershkowitz, I., Horowitz, D., \& Lamb, M. E. (2005). Trends in children's disclosure of abuse in Israel: A national study. Child Abuse Neglect, 29, 1203-1214.

Doi: 10.1016/j.chiabu.2005.04.008

Hershkowitz, I., Lamb, M. E., Katz, C. (2014). Allegation Rates in Forensic Child Abuse Investigations :Comparing the Revised and Standard NICHD Protocols. Psychology, 


\section{FACILITATING THE EXPRESSION OF EMOTIONS}

Public Policy, and Law, 20(3), 336-344. Doi:10.1037/a0037391

Hershkowitz, I., Lamb, M. E., Katz, C., \& Malloy, L. C. (2013). Does enhanced rapport-building alter the dynamics of investigative interviews with suspected victims of intra-familial abuse?. Journal of Police and Criminal Psychology, 30(1), 6-14.

Doi: $10.1007 / \mathrm{s} 11896-013-9136-8$

Hershkowitz, I., Lanes, O., \& Lamb, M. E. (2007). Exploring the disclosure of child sexual abuse with alleged victims and their parents. Child Abuse \& Neglect, 31(2), 111-123. Doi: 10.1016/j.chiabu.2006.09.004

Hershkowitz, I., \& Terner, A. (2007). The effects of repeated interviewing on children's forensic statements of sexual abuse. Applied Cognitive Psychology, 21(9), 1131-1143. Doi: 10.1002/acp.1319

Karni-Visel, Y., Hershkowitz, I., Blasbalg, U., \& Lamb, M. E. (2018, March 8-10). The association between emotional expression and children's reports of abuse: The facilitating support. Paper presented at the American Psychology Law Society Conference, Memphis, USA.

Karni-Visel, Y., Hershkowitz, I., Blasbalg, U., \& Lamb, M. E. (2018b). Emotional expression and children's reports of intra-familial abuse. Paper presented at the American Psychology Law Society Conference, Memphis, USA.

Katz, C., Barnetz, Z., \& Hershkowitz, I. (2014). The effect of drawing on children's experiences of investigations following alleged child abuse. Child Abuse \& Neglect, 38(5), 858-867. Doi: 10.1016/j.chiabu.2014.01.003

Katz, C., Hershkowitz, I., Malloy, L. C., Lamb, M. E., Atabaki, A., \& Spindler, S. (2012). Nonverbal behavior of children who disclose or do not disclose child abuse in investigative 


\section{FACILITATING THE EXPRESSION OF EMOTIONS}

interviews. Child Abuse \& Neglect, 36(1), 12-20. Doi:10.1016/j.chiabu.2011.08.006

Katz, C., Paddon, M. J., \& Barnetz, Z. (2016). Emotional language used by victims of alleged sexual abuse during forensic investigation. Journal of Child Sexual Abuse, 25, 243-261. Doi: 10.1080/10538712.2016.1137666

Kennedy-Moore, E., \& Watson, J. C. (2001). How and when does emotional expression help?. Review of General Psychology, 5(3), 187. Doi:10.1037//1089-2680.5.3.187

Klemfuss, J. Z., Milojevich, H. M., Yim, I. S., Rush, E. B., \& Quas, J. A. (2013). Stress at encoding, context at retrieval, and children's narrative content. Journal of Experimental Child Psychology, 116(3), 693-706. Doi: 10.1016/j.jecp.2013.07.009

Kuehnle, K., \& Connell, M. (2011). Child sexual abuse suspicions: Treatment considerations during investigation. Journal of Child Sexual Abuse, 19(5), 554-571.

Doi: $10.1080 / 10538712.2010 .512554$

Lamb, M. E., Brown, D. A., Hershkowitz, I., Orbach, Y., \& Esplin, P. W. (2018). Tell me what happened: Structured investigative interviews of child victims and witnesses. $\left(2^{\text {nd }}\right.$ ed.). Chichester, UK: Wiley

Laible, D. (2004). Mother-child discourse surrounding a child's past behavior at 30 months: Links to emotional understanding and early conscience development at 36 months. Merrill-Palmer Quarterly, 50(2), 159-180. Doi:10.1353/mpq.2004.0013

Lane, R. D., \& Garfield, D. A. (2005). Becoming aware of feelings: Integration of cognitivedevelopmental, neuroscientific, and psychoanalytic perspectives. Neuropsych., 7, 5-30. Doi: $10.1080 / 15294145.2005 .10773468$

Lane, R. D., Ryan, L., Nadel, L., \& Greenberg, L. (2015). Memory reconsolidation, emotional arousal, and the process of change in psychotherapy: New insights from brain 


\section{FACILITATING THE EXPRESSION OF EMOTIONS}

science. Behavioral and Brain Sciences, 38, 1-64. Doi: 10.1017/S0140525X14000041

Liwag, M. D., \& Stein, N. L. (1995). Children's memory for emotional events: The importance of emotion-related retrieval cues. Journal of Experimental Child Psychology, 60(1), 2.

Lubart, T. I., \& Getz, I. (1997). Emotion, metaphor, and the creative process. Creativity

Research Journal, 10(4), 285-301. Doi: 10.1207/s15326934crj1004_1

Lunkenheimer, E. S., Hollenstein, T., Wang, J., \& Shields, A. M. (2012). Flexibility and attractors in context: Family emotion socialization patterns and children's emotion regulation in late childhood. Nonlinear Dynamics-Psychology and Life Sciences, 16, 269.

Lyon, T.D., Scuich, N., Choi, K., Handmaker, S., \& Blank, K. (2012). "How did you feel?" increasing child sexual abuse witness' production of evaluative information. Law \& Human Behavior, 36, 448-457. Doi: 10.1037/h0093986

Marin, K. A., Bohanek, J. G., \& Fivush, R. (2008). Positive effects of talking about the negative: Family narratives of negative experiences and preadolescents' perceived competence. Journal of Research on Adolescence, 18(3), 573-593.

Doi: $10.1111 / \mathrm{j} .1532-7795.2008 .00572 . x$

Melinder, A., Burrell, L., Eriksen, M. O., Magnussen, S., \& Wessel, E. (2016). The emotional child witness effect survives presentation mode. Behavioral Sciences \& the Law, 34(1), 113-125. Doi: 10.1002/bsl.2232

Mesquita, B., \& Frijda, N. H. (1992). Cultural variations in emotions: A review. Psychological Bulletin, 112(2), 179. Doi: 10.1037/0033-2909.112.2.179

Nelson, K. (1993). The psychological and social origins of autobiographical memory. Psychological Science, 4(1), 7-14. Doi: 10.1111/j.1467-9280.1993.tb00548.x

Paine, M. L., \& Hansen, D. J. (2002). Factors influencing children to self-disclose sexual 


\section{FACILITATING THE EXPRESSION OF EMOTIONS}

abuse. Clinical Psychology Review, 22, 271-295. Doi: 10.1016/S0272-7358(01)00091-5

Pennebaker, J. W. (2012). Opening up: The healing power of expressing emotions. Guilford Press.

Pennebaker, J. W., Francis, M. E., \& Booth, R. J. (2001). Linguistic inquiry and word count: LIWC 2001. Mahway: Lawrence Erlbaum Associates.

Perls, F. S. (1969). Gestalt therapy verbatim. Lafayette, California: Real People Press.

Plant, E. A., Hyde, J. S., Keltner, D., \& Devine, P. G. (2000). The gender stereotyping of emotions. Psychology of Women Quarterly, 24(1), 81-92.

Quas, J. A., Bauer, A., \& Boyce, W. T. (2004). Physiological reactivity, social support, and memory in early childhood. Child Development, 75, 797-814.

Doi: $10.1111 / \mathrm{j} .1467-8624.2004 .00707 . x$

Rimé, B. (2009). Emotion elicits the social sharing of emotion: Theory and empirical review. Emotion Review, 1(1), 60-85. Doi: 10.1177/1754073908097189

Roberts, J., \& Taylor, C. (1993). Sexually abused children and young people speak out. In L. Waterhouse (Ed.), Child Abuse and child abusers: Protection and prevention. London, England: Jessica Kingsley.

Rogers, C. (1951). Client Centered Therapy. London: Constable.

Rohde, K. B., Stein, M., Pascual-Leone, A., \& Caspar, F. (2015). Facilitating emotional processing: An experimental induction of psychotherapeutically relevant affective states. Cognitive Therapy and Research, 39, 564-577.Doi: 10.1007/s10608-015-9680-x

Salmon, K., \& Reese, E. (2015). Talking (or not talking) about the past: The influence of parent-child conversation about negative experiences on children's memories. Applied Cognitive Psychology, 29(6), 791-801. Doi: 10.1002/acp.3186 


\section{FACILITATING THE EXPRESSION OF EMOTIONS}

Saywitz, K. J., Larson, R. P., Hobbs, S. D., \& Wells, C. R. (2015). Developing rapport with children in forensic interviews: Systematic review of experimental research interviews Behavioral Sciences and the Law, 38, 372-389. Doi:10.1002/bls

Saywitz, K. J., Wells, C. R., Larson, R. P., \& Hobbs, S. D. (2016). Effects of interviewer support on children's memory and suggestibility: Systematic review and meta-analyses of experimental research. Trauma, Violence, \& Abuse, 1-18.

Doi: $10.1177 / 1524838016683457$

Snow, P. C., Powell, M. B., \& Murfett, R. (2009). Getting the story from child witnesses: Exploring the application of a story grammar framework. Psychology, Crime \& Law, 15(6), 555-568. Doi:10.1080/10683160802409347

Styers, M. K., \& Baker-Ward, L. (2013). Finding the light at the end of the tunnel: Age differences in the relation between internal states terms and coping with potential threats to self. Memory, 21(1), 27-43. Doi: 10.1080/09658211.2012.705849

Summit, R. C. (1983). The child sexual abuse accommodation syndrome. Child Abuse \& Neglect, 7(2), 177-193. Doi: 10.1080/09658211.2012.705849

Taumoepeau, M., \& Ruffman, T. (2008). Stepping stones to others' minds: Maternal talk relate to child mental state language and emotion understanding at 15, 24, and 33months. Child Development, 79(2), 284-302. Doi:10.1111/j.1467-8624.2007.01126.x

Teicher, M. H., \& Samson, J. A. (2016). Annual research review: Enduring neurobiological effects of childhood abuse and neglect. Journal of Child Psychology and Psychiatry, 57(3), 241-266. Doi:10.1111/jcpp.12507

Vatne, T. M., Ruland, C. M., Ørnes, K., \& Finset, A. (2011). Children's expressions of negative 


\section{FACILITATING THE EXPRESSION OF EMOTIONS}

emotions and adults' responses during routine cardiac consultations. Journal of Pediatric Psychology, 37(2), 232-240. Doi:10.1093/jpepsy/jsr074

Watson, D., Clark, L. A., \& Tellegen, A. (1988). Development and validation of brief measures of positive and negative affect: the PANAS scales. Journal of Personality and Social Psychology, 54(6), 1063. Doi: 10.1037/0022-3514.54.6.1063

Wessel, E. M., Eilertsen, D. E., Langnes, E., Magnussen, S., \& Melinder, A. (2016). Disclosure of child sexual abuse: Expressed emotions and credibility judgments of a child mock victim. Psychology, Crime \& Law, 22,331-343. Doi: 10.1080/1068316X.2015.1109087

Wessel, E., Magnussen, S., \& Melinder, A. (2013). Expressed emotions and perceived credibility of child mock victims disclosing physical abuse. Applied Cognitive Psychology, 27(5), 611-616. Doi: 10.1080/1068316X.2015.1109087

Westcott, H. L., \& Davies, G. M. (1996). Sexually abused children’s and young people’s perspectives on investigative interviews. British Journal of Social Work, 26, 451-474.

Westcott, H. L., \& Kynan, S. (2004). The application of a 'story-telling 'framework to investigative interviews for suspected child sexual abuse. Legal and Criminological Psychology, 9(1), 37-56. Doi:10.1348/135532504322776843

Yegiyan, N. S., \& Yonelinas, A. P. (2011). Encoding details: Positive emotion leads to memory broadening. Cognition \& emotion, 25, 1255-1262. Doi: 10.1080/02699931.2010.540821

Yuille, J. C., \& Cutshall, J. L. (1986). A case study of eyewitness memory of a crime. Journal of Applied Psychology, 71,291-301. Doi: 10.1037/0021-9010.71.2.291 
FACILITATING THE EXPRESSION OF EMOTIONS

Table 1:

Inventory of supportive interviewer statements and prompt types

\begin{tabular}{|c|c|c|}
\hline Prompts & Definition & Examples \\
\hline Emotional support & $\begin{array}{l}\text { (1) Acknowledge, } \\
\text { contain and echo } \\
\text { emotion } \\
\text { (2) Explore expressed } \\
\text { emotions } \\
\text { (3) Explore unexpressed } \\
\text { emotions }\end{array}$ & $\begin{array}{l}\text { (1) 'You say you were [the } \\
\text { emotion expressed]/ I hear } \\
\text { what you say' } \\
\text { (2) 'Tell me more about being [the } \\
\text { emotion expressed]' } \\
\text { (3) 'How did you feel about } \\
\text { [emotional episode reported]?' }\end{array}$ \\
\hline Establishing rapport & $\begin{array}{l}\text { (1) Expressing personal } \\
\text { interest } \\
\text { (2) Making small } \\
\text { gestures of good will }\end{array}$ & $\begin{array}{l}\text { (1) 'I want to know about you and } \\
\text { your feelings better' } \\
\text { (2) 'Are you comfortable [child's } \\
\text { name]? }\end{array}$ \\
\hline $\begin{array}{l}\text { Maintaining } \\
\text { rapport }\end{array}$ & Mentioning the rapport & $\begin{array}{l}\text { 'You've already told me a lot } \\
\text { about your feelings' }\end{array}$ \\
\hline Reinforcements & $\begin{array}{l}\text { (1) Reinforcements of } \\
\text { the child's effort } \\
\text { (2) Expressing thanks } \\
\text { and appreciation }\end{array}$ & $\begin{array}{l}\text { (1) 'You express your feeling } \\
\text { very clearly' } \\
\text { (2) 'Thank you for sharing with } \\
\text { me your emotions' }\end{array}$ \\
\hline Encouragement & $\begin{array}{l}\text { Legitimating } \\
\text { expression }\end{array}$ & $\begin{array}{l}\text { 'You can talk about bad and good } \\
\text { things' }\end{array}$ \\
\hline
\end{tabular}


FACILITATING THE EXPRESSION OF EMOTIONS

Table 2:

Fixed effect estimates for the multi-level model of emotional expressions

A. Related to the interview context

\begin{tabular}{llllll}
\hline Predictors & $\boldsymbol{B}$ & $\boldsymbol{S E}$ & $\mathbf{O d d s}$ & $\boldsymbol{p}$ & $\mathbf{9 5 \%}$ CI \\
\hline (Intercept) & -3.56 & 0.11 & 0.03 & $<.001$ & $0.02,0.04$ \\
& & & & & \\
\hline Protocol - RP & 0.31 & 0.06 & 1.36 & $<.001$ & $1.22,1.52$ \\
\hline Age & 0.01 & 0.01 & 1.01 & 0.23 & $0.99,1.04$ \\
\hline Gender- Girls & 0.05 & 0.05 & 1.05 & 0.36 & $0.95,1.17$ \\
\hline
\end{tabular}

B. About the abusive events

\begin{tabular}{llllll}
\hline Predictors & $\boldsymbol{B}$ & $\boldsymbol{S E}$ & $\mathbf{O d d s}$ & $\boldsymbol{p}$ & $\mathbf{9 5 \%}$ CI \\
\hline (Intercept) & -4.66 & 0.26 & 0.01 & $<.001$ & $0.01,0.02$ \\
\hline Protocol - RP & 0.30 & 0.13 & 1.35 & 0.019 & $1.05,1.73$ \\
\hline Age & 0.12 & 0.03 & 1.13 & $<.001$ & $1.07,1.18$ \\
\hline Gender- Girls & 0.67 & 0.12 & 1.94 & $<.001$ & $1.54,2.46$ \\
\hline
\end{tabular}


FACILITATING THE EXPRESSION OF EMOTIONS

Table 3:

Fixed effect estimates for the multi-level model of substantive details

\begin{tabular}{lccccc}
\hline Predictors & $\boldsymbol{B}$ & $\boldsymbol{S E}$ & Odds & $\boldsymbol{p}$ & 95\% CI \\
\hline (Intercept) & -0.96 & 0.14 & 0.38 & $<.001$ & $0.29,0.50$ \\
\hline Protocol - RP & 0.12 & 0.07 & 1.13 & 0.096 & $0.98,1.30$ \\
\hline Age & 0.02 & 0.01 & 1.02 & 0.090 & $1.00,1.05$ \\
\hline Gender- Girls & -0.14 & 0.07 & 0.87 & 0.048 & $0.76,1.00$ \\
\hline Emotional expression to abuse & 0.46 & 0.06 & 1.58 & $<.001$ & $1.40,1.78$ \\
\hline
\end{tabular}

